\title{
The shape of things to come: museums in the technological landscape
}

\author{
Simon J. Knell* \\ University of Leicester
}

\section{Introduction}

Since the mid-1980s, museum directors have understood that the key to their success lies in how well they manage change within their organisations. The large political and economic swings of the final decades of that century demonstrated to museums in many parts of the world that they had no assurance of a future unless they could demonstrate strong and costeffective, socially and politically endorsed, benefit. The history of museums demonstrates that this has always been so: the combination of precarious museum funding and continual change has led to erratic fortunes (Knell 1996; 2000; 2001; 2004). ${ }^{1}$ Yet every generation has held optimistic beliefs about the future: 'We may fairly presume, that the most liberal support will be given to an Institution, so well calculated to promote the credit and advantage of the town, and the intellectual improvement of its inhabitants, not only in the present day but in future ages' (Whitby Literary and Philosophical Society 1826). In the present age, one such vision comes to us from Europe. ${ }^{2}$ It pictures a world altered by technologies, but within which museums have a new and critical role. It is a vision worthy of closer attention as this future is destined to engulf us all, and with its cultural diversity, social complexity, established heritage and not inconsiderable investment in technological research, Europe's concerns and experiences are likely to be widely shared. It also provides an opportunity to ask questions about how a sector of society formulates a vision of the future, what makes this vision plausible and useful, and then what history tells us about its likelihood of coming to fruition.

\section{When Culture Becomes Information}

Museums, we are told by the European Commission (EC), are at a point of transition: a 'technology-driven mutation' in the evolution of 'cultural heritage institutions' will redefine the sector and blur institutional boundaries. As Bernard Smith, the Commission's Head of the Preservation and Enhancement of Cultural Heritage Unit, remarks:

Europe's cultural and memory institutions are facing very rapid and dramatic
transformations. These transformations are not only due to the use of increasingly
sophisticated technologies, which become obsolete more and more rapidly, but
also due to a re-examination of the role of modern public institutions in today's
society and the related fast changing user demands. These trends affect all the
functions of the modern cultural institution, from collection management and
scholarly study through restoration and preservation to providing new forms of
universal and dynamic access to their holdings (European Commission 2002a:6).

A revolution is at hand. The future of museums is, so it seems from these European developments, beginning to be shaped by the visionary apparatus of technocrats; by computer scientists who have, in the recent tradition of museum operation, been servants of the museum mission. The opportunities provided by technology have developed so rapidly and become so pervasive that these workers are beginning to emerge from their backroom documentation projects to join up with academic researchers from leading university computer science departments, in order to construct a roadmap that will take museums into the future. ${ }^{3}$ Congregating around the flag of the Commission, these technologists are the inspiration and lifeblood of DigiCULT, the 'digital preservation and cultural content' domain of Europe's Information Society Technologies (IST) research programme. And their great achievement to date is in making cultural concerns a distinct component in this major research programme. ${ }^{4}$ Europe's wake-up call to the technological revolution, and its implications for world 
commerce, came with the publication of US Information Infrastructure Task Force's (USIIFT) National Information Infrastructure: Agenda for Action in September 1993. Vice President Al Gore had first backed the idea of an Information Superhighway in technology reforms introduced in 1991. In the intervening years there had been much lobbying to extend the Internet beyond the bounds of the research, defence and education communities (Malhotra et al.1995). Agenda for Action did just this, and within months Gore and Secretary of Commerce, Ron Brown, were championing major communications reforms. Europe's own vision appeared in the following June, Europe and the Global Information Society (European Commission 2002a: 23; European Council 1994). The EC began to fund ICT research immediately, and this evolved through a number of subsequent research 'Frameworks' to become the multi-billion Euro IST programme, which acquired a keen interest in culture from 1998 (Fifth Framework). Further impetus came from the European Council meeting in Lisbon in 2000. Here a commitment was made to develop a 'knowledge-based economy' and in that year the action plan eEurope 2002: An Information Society for Al/was published, recommending action on coordination, sustainability and the enhancement of digital content. A move closer to realising this plan came with a meeting of experts the following year. This resulted in the 'Lund Principles' for the coordination of digitisation programmes (European Council 2001; European Commission 2002a:44). On both sides of the Atlantic the drive was for economic prosperity and competitiveness, and consequently the private sector and marketplace have a significant developmental role. It is now a subject of global concern: the United Nations will begin a two-phase World Summit on the Information Society (WSIS) in Geneva in December 2003. ${ }^{5}$

Clearly, it is believed that an increasingly pervasive 'information society' will fundamentally alter everyday practices, and perhaps change the position of museums in society. With digitisation becoming the new watchword for access and preservation, the future for museums appears to be one of new spaces, new collections and new audiences, and rather different risks and opportunities. To prepare the sector for this future the EC commissioned a 324 page report, Technological Landscapes for Tomorrow's Cultural Economy: Unlocking the Value of Cultural Heritage (European Commission 2002a), which suggests how the sector might confront this information revolution. However, to understand this vision and its implications for museums, one needs to look to earlier research which drew up a more holistic picture of the knowledge-based, information-driven, technological landscape that is destined to become the backdrop to European life. It was developed by the IST Advisory Group (ISTAG) and conceived of a world of 'Ambient Intelligence' (Aml): ${ }^{6}$

People are surrounded by intelligent intuitive interfaces that are embedded in all kinds of objects and an environment that is capable of recognising and responding to the presence of different individuals in a seamless, unobtrusive and often invisible way (Ducatel et al 2001:1).

In this world, the invented character Dimitrios is wearing a digital avatar of himself $-a$ ' $D-M e$ ' or 'Digital Me' - which gathers data, and helps with communication and decision making. In some of the interactions the D-Me acts independently and multilingually, leaving the real Dimitrios to get on with his life (Ducatel 2001:5, 32-7). To create this kind of scenario, ISTAG considered the way technologies were developing but placed particular emphasis on human practices and needs. Technological innovation suggested that three major breakpoints lay on the road ahead: the standardisation of interfaces, which is already well advanced; developments in fuzzy matching techniques to spur on a massive growth in artificial intelligence applications; and the transition of technologies to nanoscale.

This big picture of a possible technological future has helped shape the major programme of technological (IST) research funded through the Sixth Framework, which began in 2003. Cultural heritage is a small but important 'plug-in' providing real-world content and context, and in a reflexive way this relationship is also projecting a vision of what our technologically mutated museums might look like. Perhaps unsurprisingly, the future lies not in the invention of the 'eMuseum' - a new type of museum to sit alongside ecomuseums, rural life museums, and so on - but in a reconceiving of the museum itself in a new world of opportunity. The challenge for the sector is huge, not just in terms of adapting or participating, 
but because notions of repository, evidence, authenticity, authority, preservation and access will have to change. This future may push museums more centrally into our lives or it could unleash yet more new competition into areas that were once the preserve of museums. Cultural assets (collections and sites) will continue to be key to our lives but in what form? Can digital heritage really replace the real and if so how? The World Wide Web has already blurred the boundary between exhibition and publication, and widespread museum digitisation programmes seem to push museums closer to becoming libraries. Is the distinctive role of museums challenged by this future? Will museums be reconceived, hybridised or merely altered?

\section{A Roadmap of the Present for the Future}

Technological Landscapes, the authors tell us, is 'a roadmap for action in the years to come... a reasonable view of how the cultural landscape will unfold' (European Commission 2001:31). As such it presents a linear vision in which 'cultural heritage institutions' are destined to engage with a succession of new technologies. Since billions of Euros are being put into making the ISTAG vision, or something like it, a reality, the roadmap is better described as an architectural blueprint, a plan for conducting a campaign to make it so. But the very notion of a roadmap for the sector raises all kinds of questions about the contemporary world which shapes these visions, for although it talks in the language of the future this map is very much made from components of the present; inevitably, it addresses contemporary concerns and needs, as it cannot know future ones. It is also a plan built on the political power of education and technology in modern society. It must also make assumptions about the values of culture (though it is admirably aware of how these have changed in the last ten years) and how they can be enhanced by technology; but clearly the technological drive which is implicit in this document is beyond question, since this is the very motive for the report. There are aspirations here which are reminiscent of those of nearly two centuries ago when the modern museum movement was founded:

Today, the volume of material to be digitised is the most pressing digitisation issue, and related to that, the need to select. With growing scale, the nature of object digitisation changes considerably and poses problems to cultural institutions that are not yet solved, such as mass digitisation, integration of metadata at the point of digitisation, the internal transfer and storage of huge amounts of data and, of course, the exploding costs related to all these tasks. Volume and scale of future digitisation highlight the need for automated processes and integration of object digitisation into the overall workflow within cultural heritage institutions (European Commission 2002a:16).

There is a sense of urgency and imperative here which has the hallmarks of an early nineteenth-century manifesto to build a collection and a museum. These earlier museum makers had no experience of large-scale collecting or of what a museum might become and could only learn the realities after they had built their vision. Modern digital collection makers seem to have the same relationship to their project. Initially, the museum founders saw the collecting programme as being as finite as the natural world, and collected against a specific and evolving intellectual framework. Indeed, they too were creating a pervasive new technology, offering previously unseen access to ordered knowledge built upon the act of gathering. The technological leap was no less remarkable:

Eminent metropolitan geologists, such as Roderick Murchison, looking to the provinces and particularly to the North, saw the emergence of a valuable provincial network of institutions peopled by knowledgeable curators, and containing collections ordered according to the latest stratigraphic principles. One no longer needed to rely upon raw data in the field in order to discern local geology. A scientific traveller could simply compare the museums of Whitby and Scarborough with similar institutions in Bath and Bristol. Together they formed an index to the geology of England (Knell 2000:75). 
Geology was one of the first modern disciplines to fully realise the museum as a research, reference and networked technology. And because geologists were simultaneously establishing the intellectual framework for their science, and establishing museums as a cornerstone technology of that science, they overcame the problems of interoperability.

Initially, they thought the museum was capable of concretising their actions, beliefs and values; that they really were creating a finite resource. However, they soon came to understand the error of their thinking: "no-one, who has not experienced it, can form an adequate conception of the labour of reducing into system and method the chaos of a newly-established museum, into which contributions are unceasingly flowing, and where there is as yet no adequate provision made for placing them away' (Jelly 1833:118; Knell 2000:93). The continued need to exploit the full range of social practices, which were the lifeblood of the museum, meant that collecting and donation would continue, and new intellectual fashions would be sought. It wasn't that the museum founders were bad planners, unsophisticated or lacked vision, but they had created a cultural institution which inevitably reshaped society and altered social practices, and which could not itself avoid being reshaped by those altered practices as well as by more general external change. The new technologically-enhanced museums being developed today have the same relationship to society and the future.

The Gore-Brown vision of the future demonstrates the difficulties of prediction against a background of constant social change:

Imagine you had a device that combined a telephone, a TV, a camcorder, and a personal computer. No matter where you went or what time it was, your child could see you and talk to you, you could watch a replay of your team's last game, you could browse the latest additions to the library, or you could find the best prices in town on groceries, furniture, clothes - whatever you needed (USIIFT 1993).

Remarkably, in just ten years, this vision seems to have come to fruition. Nearly all of these things are now possible using technologies. But should we be surprised at this? Just over a decade ago, technology companies were lobbying for access to the Superhighway, and they almost certainly had in mind the kinds of devices discussed in Agenda for Action. However, where this vision seems less secure is in its forecast use of these technologies. The cameraphone and the phone-mp3 player are not pervasive gadgets but niche products. While it can be argued that it is only a matter of time until these technologies come together, at present the preference remains for particular tools to do particular jobs well. This may also be the case in the future. So, in many respects, the Gore-Brown vision may be as wrong as it is right, though of course all open-ended predictions of the future have time on their side. It should also be noted that this vision had, more than anything, a political purpose: to shake up the social, economic and regulatory frameworks so as to make possible a technological future. In this regard it was highly successful and has led to remarkable technological change. Yet while technologies present us with a range of possibilities, which are configured in the visionary's dream of a new world, the market and the consumer determine an actuality much closer to the everyday. This is not to suggest that everyday practices cannot be fundamentally altered by technological change, but rather to say that societies operate through embedded cultural practices which are not so easily displaced. So while technologists accurately forecast that media would come together as multimedia, we still watch films, read books, play games, and engage with the Web like we would a vast reference book: the transformation is subtle, sometimes altering the medium without making huge changes to practices. This subtlety of difference across time and space is familiar to historians and cultural geographers; it is what we should expect of the future.

The recent history of the technologies marketplace reveals how this disparity between dream and reality has caused many a visionary to come unstuck: the bursting of the dotcom balloon in 2000 was accompanied by the collapse of the mobile phone and PC markets. 'There was this belief that everything to do with telecoms, media, software was going to be the next Microsoft. And everybody felt they had to join in. ${ }^{7}$ In the marketplace, the iterative nature of technological development can add a further impediment to the technological dream. When confronted by so many competing products and services, wider society seems increasingly 
disinclined to adopt new technologies simply for the sake of fashion. If a tool seems to do the job well then it is not updated until technologies have advanced sufficiently to make the leap essential or highly worthwhile. In 2004, low-tech texting remains the most used mobile phone technology and ringtone sales the most profitable phone-related market, while new sales of phones and contracts remain depressed. Did anyone, in 1993, think the technological revolution would lead to such mundanity? Of course, they only needed to look at television to understand how the high ideals of public broadcasting became altered in the increasingly liberated world of popular culture, entrepreneurship and market choice. At the public interface with developing technologies, it is the youth market which has the greatest concentration of disposable income and the greatest need to follow fashion, and thus the mobile phone develops on the back of products and services entirely coloured by the perceived needs of that audience. The technological leap to camera phones with their high resolution colour screens, for example, has been achieved by convincing the young that they extend the possibilities for 'eyeing up' or 'ogling'. The answer to questions about the future, then, lies just as much in the marketplace as it does in technological possibilities: the market is a powerful modifier of ideas; it is the reality check for technological dreams. So if the D-Me world is likely to arrive, will it do so on the back of impressive cultural resources or by locating a niche in the world of fashionable youth?

Despite market experiences, technological innovation continues to inspire optimism: Technological Landscapes, for example, was written at a time of great uncertainty but yet remains buoyant and confident. It was in this rather depressed technological environment that the Sixth Framework IST programme also made its bid for political support. It had three essential qualities to make it worthy of patronage. The first was plausibility: technological innovation is iterative and reasonably predictable, and because of this it involves fewer risks. The second was social and economic relevance: westernised society has long headed in the direction of greater technological innovation and thus has associated with it huge potential markets. The EC's own research also suggested that technologies were being replaced on a 2-5 year cycle, causing major problems for business (European Commission 2002a:15). Thirdly, the plan is built around a vision which suggests a better future.

However, many of the promises of this new technological future have already been realised in one form or another - we are in an iteration - and the contrast between it and now does not seem as great as it was in 1993 when Gore was speaking to an audience still using MS-DOS. The modern desktop PC, for example, has capabilities beyond the needs of most applications. Technologies are part way through this revolution and they no longer offer the promise of the entirely new so much as the enhanced. It is when technological development gets to this stage that the market seems to put developers under pressure.

It is in business and manufacture - which can be both producers and users - where the sting of technological change is most sorely felt in profit margins. Were most museums involved in a competitive 'cultural economy' akin to the world of manufacture (as Technological Landscapes, with its rather too vague notion of 'cultural heritage institutions', implies), the situation would be different but this is not currently the case. As users of technologies, most museums are rather closer to the domestic user. Some may develop systems on a larger scale but the majority will rely upon mainstream technologies with a few bespoke enhancements (such as collection databases). They must make decisions based upon their powers to upgrade and migrate content, but constrained budgets restrict those choices. Fortunately the domestic market seems ready to take up opportunities which are also of great use to museums, such as Wi-Fi. This keeps technologies inexpensive and user-friendly.

What technologists have come to understand is that technologies are not taken up if content is inadequate (hence the rise of texting and the failure of WAP) ${ }^{8}$ Future online services require a critical mass of quality content, and the proven popularity of museums on the Web suggests a natural way forward. Certainly there is a relationship of mutual benefit here between those who wish to develop new technological solutions and the content-holding institutions who wish to develop new audiences. And as cultural materials in museums, libraries and archives are traditionally available 'free', they also present a relatively unproblematic resource into which to tap. This relationship has given the DigiCULT initiative a certain prestige and political weight, but it has also had the benefit of bringing computer scientists into contact with 
the complex realities of modern museum values of integrity, authenticity, authority and so on, and a whole host of relativities from the humanities. These are notions critical to the development of 'intelligent heritage' and an inclusive 'knowledge-based society'.

The problem for this group, however, is that it must frequently deal with all-embracing concepts, such as the 'cultural heritage institution', which have no real-world basis. The European view tends to focus at this macro level, one of national governments and national museums, and although it calls for support for smaller organisations, the fact is that it is a vision built out of the experiences of a heterogeneous assemblage of larger institutions. In contrast, it is Europe's long-established cultural diversity which gives it great cultural advantage but which is also its greatest impediment to integrated thinking. The repeated assertion, for example, that 'In the Information Society, in the long run, only the digital will survive in the memory of a nation as it is more readily available and accessible than analogue cultural heritage resources' (European Commission 2002a:38, 45), is a product of this macro perspective. Clearly, cultural heritage is, as far as museums and tourist agencies are concerned, valued primarily for its materiality. Similarly, in a related publication discussing digital objects and authenticity, there seems to be suggestion that cultural materials are entirely composed of easily extractable information (European Commission 2002b). The group discussing this problem, it turns out, was composed entirely of archivists and librarians, and consequently the fundamentally more complex issues of capturing material culture were not discussed (though clearly this is a component of library and archive holdings too).

\section{Digital Collecting - Unshackling the Museum}

It is an information scientist's perspective, perhaps, which seems to encourage a belief that the thing only becomes real when it is captured in a digital form and converted into information. However, the next generation of museum professionals might decide that all collecting is a selective process of capturing information, and perhaps the step from collecting real objects to collecting digital representations of them is not too great. While we understand the museum as based around the collection of objects, the burden of collections leads to unwieldy and inflexible organisations unable to live within their means and frequently struggling to achieve their goals. The histories of collecting reveals how successive collection-holding institutions (learned societies, for example) have outgrown the need to collect, locating instead refined intellectual and educational goals which dispense with the need for a repository. The collection is then passed on to other organisations until it achieves the ultimate goal of a place in a publicly-funded museum.

Collecting, as a core museum practice, is complex and largely beyond scientific rationalism. It is an act of authorship and connoisseurship. It is a physical interpretation of a set of circumstances or body of potential data. The object is thus placed within a collection according to an individual's beliefs. The power of authorship has been challenged in the museum over the last two decades but collecting is impossible without it. The question then arises, how are things altered if we collect digitally without retaining the real thing? The President of the Bundesarchiv, Germany, believes future archival collecting will be of two types: critically important material will be preserved; other important material will simply be captured in digital form (European Commission 2002b:9; Knell 2004). In the museum, the photograph or drawing already acts as a surrogate for the real thing; a digital representation will be no different. It is here, where no object is preserved, that the power of authorship becomes critical, so as to ensure that the digital object is authoritative and legitimate, regardless of the inevitable bias and individualism that is found in all authored work. Disciplinary rules and frameworks will become even more important to the collecting exercise in this digital future as the possibilities for re-examination and a second opinion are strictly limited.

One often remarked-upon concern here is the increased potential for forgery in the digital collection. However, it is doubtful that a move to the digital will necessarily pose increased risks for museums in this regard. Forgers have already successfully managed to produce paper documents, which are indistinguishable from the historic examples they are purported to be, and inserted them into museum archives. ${ }^{9}$ Similarly, fakers of Chinese 
ceramics read the scientific papers of the ceramics experts in order to make sure their fakes pass currently favoured authenticity tests (Tseng 2001). In some respects digital collections can be offered greater protection. In museums, a theft or contamination invariably results from the perpetrator gaining physical access to the collections and associated archives, often in the guise of a legitimate visitor. In the digital collection, no user need have access to the master image or record; access is always through the copy which can be destroyed after use (in other words, digital objects become accessible only through a form of publication). A further reduction of risk arises from keeping things (digital objects) which, unlike paintings and sculpture, have no value in the art and antiquities marketplace. In the digital realm of trusted repositories with effective security, perhaps the greater risk is the accidental misrepresentation of the object through errors of interpretation, capture or record making. Recently, technologists have suggested that a record of the processing history be kept, just as museums keep object history files to help them decide questions of authenticity (Research Libraries Group and Online Computer Library Center 2002).

Much of the discussion taking place in Europe has been dominated by librarians and archivists who are confronting the issues of 'born digital' material. This is apparent in the preferred language of Europe where there is frequent reference to 'digital preservation'. This phrase is only useful in the realm of easily transferable information. Museums' material concerns make 'digital preservation' an oxymoron. ${ }^{10}$ Similar misunderstandings arise from referring to the museum's digital collection as a 'digital library'. The digital museum collection will be as impenetrable as the physical collection, as it is the result of the same complex disciplinary practices; the museum collection is not like a library, its collections are not so easily read. These important distinctions suggest that the digital futures for the museum and library are also destined to be distinctive.

While computer scientists understand that rapid technological change will require the migration of content onto successive new media, there are other issues that will undermine the permanent value of the digital museum resource. I shall mention just two. The first of these arises from the mutability of the meanings and understandings of collected things. To an audience who has experienced the stomach-churning cinematography of the 2001 television series Band of Brothers or read Antony Beevor's, harrowing 1998, Stalingrad, the 1962 film The Longest Day will seem a lie and an inauthentic representation of the Second World War. The Longest Day crystallised the values and sensibilities of 1960s society; Band of Brothers responded to earlier war movie genres with a new desire for authenticity. In these examples, there are subtle differences in the medium and the way it was used. The medium of film changes, responding to a context (cinematography, technology, artistic innovation, fashion, aesthetics and so on), which both alters the author and the medium. And while these examples are constructed narrative tales, the digitised images of cultural objects and sites - although less obviously so - have the same qualities: they are shaped by the medium and by the hand of the author. These, in the same way, date stamp an interpretation, in a way that a kept object does not. While both image and object can be reinterpreted, the first is to always be read through the filter of the medium.

While medium of capture places constraints on the outcome, the possibilities for use can also shape the act of capture. This will be my second example. In the museum, the real object is capable of being an archival resource, a site of meaning making, a component in an educational programme, primary data in a research project and so on. But museums tend to select different objects for different jobs; a tattered item of costume might present a researcher with critical clues to an aspect of textile history but will never form an exhibit. The question, then, is how should the object be digitised to preserve its essential characteristics? When we digitise a 1960s miniskirt do we invest in high resolution capture of lining, buttons and zip or just capture an overview? The answer to these questions lies in intended use: if for research then the answer is 'yes', if for display then 'no'. The answer affects both the mode of capture and the quality of the dataset. The contrast between these two uses also extends to the degrees of liberality of interpretation and resolution that become captured in the image-record. This tends to give permanence to acts which only exist temporarily in the museum. The more liberal interpretation of educators and exhibitors exists only for the period of engagement with an audience, while the objects themselves exist for the most part in the world of the specialist 
where more pedantic forces of integrity and authenticity predominate and, ideally, associate an arcane dataset with the object. Thus the digital object - for the purposes of efficiency - may be a further compromise.

Digitisation, then, offers new possibilities to collect but also new forms of constraint. But it may enable museums to reduce the quantities of objects they collect physically, without sacrificing much in the way of making a record, and thus mitigate some of the high costs of keeping which make collecting expensive. The costs of collecting (acquisition) itself will probably remain unaltered. And while the possibilities of storing vast quantities of data cheaply might cause computer scientists to fantasise about the new possibilities of digitally capturing whole archaeological sites and making them available online, such dreams - however real they become - are for the moment exercises in technology. The curator of the digital collection will need to learn new levels of restraint to counter the ease with which a digital camera can be used. Museum costume collections frequently contain the cast off clothes of curators and without a professional framework it would be all too easy for the next generation of costume curator to succumb to the world of the snapshot. So, although these new digital collections, internalised within machines, are remote, the tasks associated with them, as the EC recognises, remain essentially curatorial: objectification, classification, selection, ordering, keeping, exploitation and disposal. While technologists might feel they have the reins of technology, it will be specialists in culture, and more indirectly their political masters and their publics, who will decide which technologies to endorse.

\section{New Access, New Income}

Education, or rather 'the educational market', is seen as driving digitisation programmes (European Commission 2002a:19). ISTAG clearly saw Ambient Intelligence as contributing significantly to future education and learning, although it was uncertain whether this would deinstitutionalise the sector or strengthen institutional players, such as universities and museums (Ducatel et al. 2001:15). Given the high costs of providing online learning, and the high level of institutional accountability and support required, together with the need for assurances of authority, integrity and authenticity, these institutional players have a strong future provided costs of delivery can be contained. Competition, however, will grow as ease of access increases, a development already seen in the distance education sector but which might also affect the museum provision of online resources to schools. The ISTAG vision suggests that learning will become more diverse, pervasive and accessible, and it places a high value on the increased possibilities of social learning, although technologies already have a proven track record in this area. ${ }^{11}$

Culture will have an increasingly important role as learning becomes more accessible and flexible. The European vision for the culture sector, frequently talks about the 'true value' of culture:

Thus, European cultural heritage institutions not only hold the key to a treasure chest of unique resources, they also have the potential to turn the key to unlock the true value of our rich cultural heritage (European Commission 2002a:12).

Technological Landscapes is not just referring to the power of technologies here. The report repeatedly emphasises the importance of museums' intellectual capital which recognises not just the collections but more particularly the peculiar qualities of the workforce, and indeed those qualities that have been most under attack in the last decade. However, whether technology can unlock the true value is not beyond question. Television companies, such as the BBC, which hold archives of past programmes, have new opportunities to realise the commercial worth of their holdings (European Commission 2002a:11). Closer to the world of museums, libraries may be able to reveal the true value of their collections by converting them to easily searchable e-texts. In contrast, the museum's digitised object is merely a compromise. The power of the real thing is sacrificed, and replaced by access to an image, even if that image can be manipulated. Is this simply a form of interactive publication or can the digital exhibit really offer something akin to a museum experience? Certainly access is extended as online content is not constrained by the linearity of the publication, delicate objects become visible, 
the storehouse is opened up and collections become accessible to remote communities. Haptic technologies might even allow those communities to sense that they can hold and touch these virtual objects. Yet, no matter how one animates the digital object or captures it in high resolution, the object received through a monitor seems remote. Its materiality, its being, its existence as proof, as evidence - its true value - remains illusive. The emotive experience of seeing the real requires the real and no surrogate will do. A virtual visitor may understand the thing better and be better prepared to interpret it when they see it but they receive those peculiar attributes of real things only through real world engagement. Haptic technologies seem to offer the potential to dissolve this barrier and give a sense of a tangible reality, but, as yet, that sense of tangibility is simply an illusion no different from 3D and '4D' cinema.

If technologies do have the power to open up the true value of the museum object then, from a contemporary museum perspective, they do so in a complementary fashion. In the comfort of our own homes, interacting with an online resource, a cup of coffee by our side, the chance of a successful learning outcome is heightened. In contrast, during a museum visit, we are not inclined to read labels and soon get tired of walking, standing and staring, and also tired, perhaps, of the curator's singular approach to interpretation. Increasingly, the real things before our eyes lose their appeal as we fight with our body's instincts for more active engagement and more comfortable surroundings. But yet, stood before that Gauguin, Braque or Picasso we see the brushstroke and the illusion of the glossy image of books and webs dissolves into a coarser and more craftsman-like object; the painting moves from art historical icon to something very clearly of human manufacture. This is what we can, in the right circumstances, learn in museums and it seeps in through our every pore provided we are equipped to interpret the object. Unfortunately, to achieve this level of appreciation one needs to go into the gallery with a little information - one cannot appreciate art or anything else museums collect and keep, simply by looking at it, or indeed by touching it. A little prior knowledge enhances the museum visit immeasurably. However, suppose the visitor takes her own D-me into the gallery as her own interpretative assistant. Perhaps now some of the pain is removed: she is given the information she wants and she is told what she should see. The leap to personalised interpretation is not that great - wireless technologies are already making available context-aware information to visitors - and this offers the greatest potential for turning museums into inclusive spaces. ${ }^{12}$ The same personalisation of technology also means that networked online information resources can be interpreted according to local context: an English steam locomotive, for example, might be interpreted differently for the viewer in India, Poland or Bolivia. There are, of course, many contentious objects and interpretations in museums - Enola Gay being a famous example - which might respond well to this kind of personalised interpretation. However, there are also dangers in permitting the public to hear only what they want to hear, and museums will still want to control the thrust of the interpretation and present their audiences with challenges.

Technologies do open up the possibilities for sophisticated interpretation which can come close to challenging the object in terms of being the ultimate repository of knowledge. A prime example of this is Kevin Kiernan's Electronic Beowulf, a project began in 1993 when its intentions were beyond the capabilities of contemporary technologies. A joint project of the British Library and the University of Kentucky, it was published as a CD-ROM at the end of that decade. High-resolution images of the $11^{\text {th }}$ century manuscript were combined with a range of other resources which revealed hidden detail in the object. Although only a composite of images of the real thing, for most uses it is unquestionably more useful than the real thing. The CD-ROM contributes to the preservation of the real thing by leaving it undisturbed and in doing so it largely replaces it as the material culture at the heart of modern English studies.

The digital object, then, although having weaknesses when compared to the real, can also be manufactured to have superior strengths in terms of usability. In the same fashion, the digital exhibit might then compete successfully with the real experience. David Bearman, of Art Museums Image Consortium (AMICO), USA, sees interactivity as a competitive factor in these virtual environments: 'Those resources that you cannot manipulate will be perceived as second rate... Moreover, the museums they come from will be perceived as second rate' (European Commission 2002a:12). We know from the web that the latest technologies can enhance the overall feel of a site - the semiotics of fashion and novelty may increase the 
effectiveness of communication - but we also know that quality of information, effective design, comprehensiveness, authority and so on make for reasons to visit. Interactivity was a museum buzzword in the 1970s and 1980s, but it too has been questioned, particularly with the rise of the modern edutainment centre where there is often no logical point to the interaction and no relationship between action and outcome, and where - because there are no real objects - intellectual depth is illusive. However, Bearman is right in flagging up interactivity as a desirable addition to what is possible in the museum but it is not a concept that has any value in isolation. In the ultimate interactive digital environment - that of 3D gaming - gamers judge the success of a game not simply in terms of interactivity but in strong narrative, plausibility, creativity, and intellectual and imaginative depth. These are also values of museums and of the arts in general. The key to communicative success lies not in the ability of an organisation to construct an educational experience or the technician to make things interactive, but in the intellectual creativity of the organisation. The Beowulf project was an act of scholarship but most critically one of considerable creativity and vision. To its great credit the EC's vision repeatedly values these qualities in museums - even if overplaying market possibilities: 'Cultural institutions should build on their strengths, authenticity, knowledgebased interpretation and contextualisation, and use new technologies to develop their own niche markets for licensed resources' (European Commission 2002a:18).

The museum, then, is unlikely to be replaced by a digital entity, just as the electronic book has not eradicated the paper version, and the desktop PC never did create the paperless office. Technologies tend to sit side by side, each ideal for its own task; a view which perpetuates a belief that the future will continue to be one of specific tools for a specific jobs. Technological Landscapes frequently refers to cultural institutions becoming hybrids of the real and the digital. Indeed, this marriage might offer the possibility of reshaping a failing and unaffordable museum into a leaner centre for knowledge, expertise and learning. Let me use a traditional small town museum somewhere in the English midlands to explain what I mean. This museum is run by a small team, and occupies old building with more space than it can maintain. The visitor experience consists of poorly interpreted objects of a kind seen in many local museums in Britain. They do little to stir the imagination. The staff are imaginative but there is clearly too little revenue funding here to really make a go of it, and in the glossy, connected, interactive, immersive, click-of-a-mouse world increasingly available to the majority of its visitors, its future looks bleak. But, on my last visit, there in the corner of one of the galleries, I noticed an old photograph of some ancient urns still in the ground. The picture was from the early twentieth century and showed a street not far away which was then being built. Next to the photograph was one of the pots. Here was an interpreted object, an object which speaks of the historical event of its discovery, and of the deep past it exposed. Suddenly this pot becomes real, concrete and powerful. Clearly, the objects here do still retain their powers but they lay behind a veil of neglected interpretation. Perhaps a better future for this museum is to slim down the enterprise, to put the most important material into compact storage, reduce the size of the buildings and physical holdings, and make a major commitment to online interpretation - narratives and reference materials - and digital collecting. A temporary exhibition space or two could be created and used to cycle themed and wellinterpreted displays, support school visits and act as a venue for community activities. If these complementary resources are sold to schools, and better commercial use is made of the photographic archive - perhaps making attempts to exploit the genealogical market by marrying the content of collections with data in the local archive and local studies library - then perhaps a more sustainable and effective museum is created. The audience is extended, technologies and institutions are working in a complementary fashion, and the real, by this means, also gains a more secure future. In the process of responding to new opportunities to improve interpretation and access, the museum is fundamentally redefined and reborn.

\section{The Shape of Things to Come}

Before the downturn in the dotcom market, there was much talk of the profits that could be made from online connectivity. There were global markets to be captured and the development of the Superhighway reflected an economic vision. As Bangemann put it, 'Citizens and users 
will benefit from a broader range of competing services.' The continuing decline in traditional museum revenue streams in many parts of the world has made museums cost aware and opportunity seeking. External pressure to change has pushed them into consultancy and turned their names into brands on everything from greetings cards to household paints. That Technological Landscapes detects this economic shift in thinking in the culture sector (European Commission 2002a:133), and refers to the 'cultural economy', is partly because the European Community is first and foremost an economic partnership, and its research programmes are centred on achieving a healthy environment for market competitiveness. Though they aspire to independent financial solvency, museums rarely operate in a market where direct payment for services secures their funding. The economic value of museums is indirect: a pervasive influence on tourism, education, leisure and a liveable environment, which provides direct economic benefits for a range of businesses but not necessarily for the museums themselves. It is here where the economic benefits of museums are most felt that they remain least measurable or attributable. Contributions of this type, which most justify their economic cost, tend to depend on museums being situated in a specific place. In contrast, digital heritage is often about making resources ubiquitous: the virtual Louvre is available to everyone but it only reaps economic benefits if tourists are drawn to visit Paris. Smaller museums making their high quality exhibits available online could conceivably undermine the potential for visits by providing content which might satisfy the needs of potential visitors or reveal that this museum isn't for them. Without online access even the visitor who enters and leaves in revulsion is a click on the counter, a visitor figure to weigh against the cost of the museum.

It is unclear if museums will be able to generate an income from technologicallyenhancing their collections and interpretations, but Scottish Cultural Resources Network's (SCRAN) agglomeration of exclusive and enhanced resources may suggest a way ahead. With some $£ 15$ million in government pump-priming, SCRAN has rapidly developed a critical mass of digital resources which can be combined in a range of interpretive and educational contexts. Access for schools and individuals is via subscription. Museums benefit from having their digitisation activities externally funded, and preserve other rights. It is an excellent example of creative thinking which for the moment appears to have succeeded (Royan 2000; European Commission 2002a:54, 123)..$^{13}$ Yet, as Technological Landscapes detects, such enterprises, unless they find a unique niche, are at risk from the activities of 'spoilers' such as New York Public Library, the Library of Congress, and Massachusetts Institute of Technology who, as they receive their income from patronage and other sources, freely put material online. However, SCRAN, like other CultureNets around the world which have secured government funding (e.g. Scandinavia, Mexico, Latvia and Hungary), is now too fundamentally important to Scottish nationhood to be permitted to fail. Free access is, of course, a fundamental philosophical ingredient of the Web. It has also been a long-established belief of the museum and library fraternity.

Like CultureNet developments, the European Commission (EC) necessarily operates at the level of governments, yet culture tends to be locally grown and locally supported. It is built around a sense of identity whether dealing with the science of palaeontology, saving the local canal or reflecting the Scottish nation. Such local enterprises, and the institutions they spawn, put themselves first, and their involvement in collaborative exercises usually results from selfish or mutual concerns (rather than from altruism). For some twenty years museums have operated in this opportunistic way and they will continue to do so. Today, numerous opportunities lie in technologies, and museums will examine them as a means for improving services, achieving efficiencies and generating income. They recognise that involvement will have short-term benefits, but that in a year or two they will need to find some other source of income. By this means, and by exploiting their communities of practice (Wenger 2000; Wenger et al. 2002), ${ }^{14}$ (and not inconsiderable government investment) museums have survived.

From a continental perspective, the EC sees a need for paternalistic actions by governments to ensure efficiency, sustainability and inclusion. While such strategic thinking should be met positively, the experiences of museums reveal relatively few sustained examples of strategic planning. ${ }^{15}$ Individualism and localism, which create value in culture, are 
not so open to government control, but while these give the sector a certain strength they also undermine strategic desires for efficiency and sustainability (see European Commission 2002a:13, 43 for structural actions). It may be that strategy might develop only in supporting measures: CultureNet portals represent strategic attempts to bring together a range of resources in highly imaginative ways which also wave the national flag. Consequently, they have proven attractive to governments both in terms of funding and involvement. However, the cultural assets they configure arise out of more chaotic local circumstances.

Seventy years ago, HG Wells' published The Shape of Things to Come a novel in which the fictional Dr Philip Raven left to the author notes on 'a history of the future'. It forecast a second world war that would lead to the destruction of the world. Like other artistic visions, it was painted from the palette of his present, configuring a world that also owed much to his past. The actuality of the future echoed Wells' predictions but only in terms of a present successively reconfigured and revisited; for all his social awareness and experience of future predicting he did not describe a future that came to be. Technological Landscapes predicts the future using the same tools, it is a rich reflection of the present and inevitably aspects of the present will be inherited by the future, just as they were for Gore and Wells. In Wells' vision, the future landscape is one of remarkable underground cities imaginable in 1933; Ridley Scott's 1980s Blade Runner similarly sweeps aside the historic landscape but here constructs a future reflecting the pessimism of that decade. Technological Landscapes promises a futuristic landscape of pervasive technologies and arises from the irrepressible optimism of modern science. The revolution, however, is largely one for information and computer scientists who wish to turn the anarchic mass of digital information, currently available to the public, into an intelligent resource of 'semantically rich, adaptive information contexts' (European Commission 2002a: 105; 2003). If they succeed, then a revolution for museums may follow. Their attempts also mirror those of the world that gave birth to the modern museum. Nearly two centuries ago museums emerged from nothing to populate every major conurbation in provincial England. They did so in the timescale of present technological cycles -3 to 5 years. However, it was not long before the circumstances which led to their emergence evaporated and museums then had to find other roles and purposes (Knell 2000:285). Even today, museums are being born as new technologies for identity, communication, learning and social interaction (see, for example, Huang 1999:249).

The role for museums in the information revolution which lies before them remains unclear. They will be fundamentally affected but their relationship to information is rather different from that of the library and archive; museums are places of authorship and constant reinvention. Museums will face up to this challenge in their usual opportunistic fashion: through institutional and personal adaptability; the pragmatic exploitation of opportunities which arise from change; and the use of long-established collaborative methods of working. Technological Landscapes is undoubtedly a rich and complex vision and one that must be welcomed. But it also conceals considerable diversity of provision: it is not a consensus view but a collection of inevitably personal interpretations. By concertinaing this diversity into the term 'cultural heritage institution' the roadmap loses some of its definition. It is as though the rivers, roads and railways on this map have all been coloured the same. For the most part the museum response to this technological revolution will not be strategic or, indeed, necessarily sustainable. It will be one of creativity, diversity, individualism and opportunism. This, at least, is what history tells us about the way museums managed change in the past and there is little reason to think that this won't also be true in the future.

\section{References}

Department of Education and Science (1973) Provincial Museums and Galleries. London: HMSO.

Ducatel, K., Bogdanowicz, M., Scapolo, F., Leijten J. and Burgelman J-C. (2001) ISTAG: Scenarios for Ambient Intelligence in 2010, ISTAG report, Brussels: European Commission, ftp://ftp.cordis.lu/pub/ist/docs/istagscenarios2010.pdf 
European Commission (2002a) Technological Landscapes for Tomorrow's Cultural Economy: Unlocking the Value of Cultural Heritage, DigiCULT Report, Luxembourg: Official Publications of European Communities. http://www.digicult.info/pages/report.php

European Commission (2002b) Integrity and Authenticity of Digital Cultural Heritage Objects, DigiCULT thematic issue 1, http://www.digicult.info/downloads/thematic issue 1 final.pdf

European Commission. (2003) Towards a Semantic Web for Heritage Resources, DigiCULT Thematic Issue 3, http://www.digicult.info/pages/Themiss.php

European Council (1994) Europe and the Global Information Society (Bangemann Report), Brussels: European Council http://www.medicif.org/Dig library/ECdocs/reports/ Bangemann.htm

European Council (2001) European Content in Global Networks: Coordination Mechanisms for Digitisation Programmes (Lund Principles), ftp://ftp.cordis.lu/pub/ist/docs/digicult/ lund_principles-en.pdf

Huang, K.-N. (1999) New Visions for Museums, Taipei: National Museum of History.

J[elly], H. (1833) 'Biographical sketch: J.S. Miller', Bath and Bristol Magazine or Western Miscellany, Vol 2, 111-22

Kiernan, K.S. 1993. 'Digital preservation, restoration, and disseminatin of medieval manuscripts', in A. Okerson (ed.) Scholarly Publishing on the Electronic Networks, Proceedings of the Third Symposium, http://www.uky.edu/ArtsSciences/English/Beowulf/eBeowulf/main.htm

Knell, S.J. (1996) 'The roller-coaster of museum geology', in S.M. Pearce (ed.) Exploring Science in Museums, New Research in Museum Studies, London: Athlone, 29-56.

Knell, S.J. (2000) The Culture of English Geology 1815-1851: A Science Revealed Through Its Collecting, Aldershot: Ashgate.

Knell, S.J. (2001) 'Collecting, conservation and conservatism: late twentieth century changes in the culture of British geology', in D.R. Oldroyd, (ed.) The Earth Inside and Out: Some Major Contributions to Geology in the Twentieth Century, London: Geological Society, 329-51.

Knell, S.J. (2004) 'Altered values: searching for a new collecting', Museums and the Future of Collecting, Second Edition, Aldershot: Ashgate, 1-46.

Malhotra, Y., Al-Shehri, A. and Jones J.J. (1995) 'National Information Infrastructure: myths, metaphors and realities', http://www.brint.com/papers/nii/

Markham, S.F. (1938) The Museums and Art Galleries of the British Isles, Edinburgh: CUKT/ Constable.

Miers, H.A. (1928) A Report on the Public Museums of the British Isles. Edinburgh: Constable.

Research Libraries Group and Online Computer Library Center (2002) Trusted Digital Repositories: Attributes and Responsibilities, Mountain View California:RLG, http://www.rlg.org/ longterm/repositories.pdf.

Resource (2001) Renaissance in the Regions: A New Vision for England's Museums, London: Resource.

Rosse, Earle of. 1963. Survey of Provincial Museums and Galleries, London: Standing Commission on Museums and Galleries, HMSO.

Royan, B. (2000) 'Scotland in Europe: SCRAN as a Maquette for the European Cultural Heritage Network', Cultivate Interactive, 1, http://www.cultivate-int.org/issue1/scran/

Standing Commission on Museums and Galleries (1979) Framework for a System of Museums, London: HMSO. 
Tseng, S. 2001. The ArtMarket, Collectors and Art Museums in Taiwan since 1949, Unpublished $\mathrm{PhD}$ Thesis, Leicester: University of Leicester

US Information Infrastructure Task Force (USIIFT) (1993) National Information Infrastructure: Agenda for Action, Washington, DC: National Commission on Libraries and Information Science. http://www.ibiblio.org/nii/toc.html

Wenger E., McDermott, R.A. and Snyder, W. (2002) Communities of Practice: A Guide to Managing Knowledge, Boston: Harvard Business School Press.

Wenger, E. (2000) Communities of Practice: Learning, Meaning and Identity, Cambridge: Cambridge University Press.

Whitby Literary and Philosophical Society (1826) Annual Report, 3.

\section{Notes}

${ }^{1}$ I have reviewed the history of museum desires for the future in a number of publications, and also neglect and decline in 'Collection loss, cultural change and the second law of thermodynamics', presented at the Society for the History of Natural History Conference, Lost, Stolen or Strayed: The Fate of Missing Natural History Collections, Leiden, May 2001.

${ }^{2}$ The subject for this paper arose from attending a DigiCULT event early in 2003. Here I found a community, distinct from that to be found in the world of museums and museum studies, planning the future of museums, libraries and archives. As someone interested in communities of practice and change in museums, this was clearly an interesting topic for a paper. Aspects of this paper were delivered at the international colloquium to launch M Museos de México y del Mundo at the National Museum of Anthropology in Mexico City and at the Museum Directors' Forum at the National Museum of History, Taipei in 2003. I am very grateful to Miguel Fernández Félix, Marco Barrera Bassols and Kuang-nan Huang for inviting me to speak at these events.

${ }^{3}$ Seamus Ross, Humanities Advanced Technology and Information Institute, University of Glasgow, correctly expressed the view that this technological development requires the leadership of computer scientists rather than museum professionals (S. Ross on 'Digital preservation research opportunities' speaking at the European Commission IST Digital Culture workshop Mapping the Future, Luxembourg, 28 January 2003). But, as I suggest here, this technological leadership does not necessarily extend to the application of these technologies in museums and related organisations.

4 The DigiCULT websites contain a wealth of material: http://www.cordis.lu/ist/ka3/digicult/, at http://www.cordis.lu/ist/directorate e/digicult/index.htm and http://www.digicult.info/pages/ publications.php

${ }^{5}$ The second phase is in Tunisia in 2005. For WSIS, http://www.itu.int/wsis/. For European involvement: Communication from the European Commission to the Council, Towards a Global Partnership in the Information Society: EU Perspective in the Context of the United Nations WSIS, Brussels, 19.5.2003 COM(2003) 271 final.

${ }^{6}$ For ISTAG reports see http://www.cordis.lu/ist/istag-reports.htm, and for the work of the group more generally see http://www.cordis.lu/ist/istag.htm.

7 Tony Dye, Investment Manager, Phillips and Drew, quoted by Mike Verdin, 'Dot.Com doomsters see more share falls', BBC News, 12 March 2002, http://news.bbc.co.uk/1/hi/ business/1854227.stm.

${ }^{8}$ WAP, or wireless application protocol.

9 John Drewe famously contaminated the archives of the Tate Gallery and Victoria \& Albert Museum in the 1990s in order to perpetrate a series of art frauds.

${ }^{10}$ Paul Fiander makes this point in relation to the migration of the content of vinyl records onto 
CDs, and the consequent loss of the authentic in European Commission (2002:12).

${ }^{11}$ See, for example, the pioneering work of the Jason Project, http://www.jasonproject.org/. eSchoolnet provides European collaborative learning and was just one example in operation before this ISTAG report was published, http://news.eun.org/eun.org2/eun/en/ index eschoolnet.html

12 Tate Modern, London, piloted the use of portable wireless connected interactives in August 2002 but many museums are currently establishing wireless networks for the use of their visitors.

${ }^{13}$ See also Technology Advisory Service for Images (TAS $I$ ), 'SCRAN case study' at http:// www.tasi.ac.uk/resources/scran.html.

${ }^{14}$ European Commission (2002a:80) suggests that cultural institutions 'adapt to the network logic' but clearly this has been something at the core of museum practice for more than two centuries.

${ }^{15}$ A century of British reports, for example, failed to stimulate action: (Miers 1928; Markham 1938; Rosse 1963; Department of Education and Science 1973; Standing Commission on Museums and Galleries 1979; Resource 2001). In contrast, museums in Spain are currently moving towards an integrated service. At the same time, museums in France enter a more fragmented phase.

*Simon Knell is Head of the Department of Museum Studies at the University of Leicester. His research concerns the operation of communities of practice in museums and in the science of geology. These have been investigated in historical studies spanning the last two centuries. $\mathrm{He}$ has also written much on museum collecting and is currently writing a book on material culture and communities of practice in palaeontology. 